\title{
Aspectos semânticos e morfossintáticos de deonticidade em entrevistas do Corpus Sociolinguístico da Cidade do México ${ }^{1}$
}

\section{Semantic and morphosyntactic aspects of deonticity in interviews of the Sociolinguistic Corpus of Mexico City}

\author{
Jane Eyre Martins Caldas (UFC) ${ }^{2}$ \\ Nadja Paulino Pessoa Prata (UFC) $)^{3}$ \\ André Silva Oliveira (UFC) ${ }^{4}$
}

Resumo: Este trabalho tem por objetivo fazer uma descrição e análise da qualificação da modalidade deôntica em termos dos aspectos semânticos e morfossintáticos envolvidos na instauração dos atos deônticos no gênero entrevista. Para isso, tomamos por base os pressupostos teóricos da perspectiva funcionalista, em que os estudos relativos aos fenômenos linguísticos devem ser descritos e analisados com base no uso efetivo da língua. Nesse sentido, recorremos ao Corpus Sociolinguístico da Cidade do México (CSCM), a partir do qual coletamos 20 entrevistas. Após a análise quali-quantitativa, constatamos que a fonte deôntica instaura um determinado valor modal deôntico (obrigação, permissão ou proibição) sobre o alvo deôntico, considerando o tempo gramatical (presente, futuro simples ou condicional simples) e a forma de expressão (auxiliares modais) adequados, de modo que possam espelhar os propósitos comunicativos do falante no que tange à asseveração ou à mitigação dos conteúdos modais deônticos, localizando o evento sobre o qual recai a deonticidade para o momento da enunciação ou para um momento futuro, o que intensifica a deonticidade expressa, devido ao fato de esta modalidade ser considerada como orientadapara-o-futuro.

Palavras-chave: Funcionalismo. Modalidade deôntica. Semântica. Morfossintaxe. Espanhol.

Abstract: This work aims to describe and analyze the qualification of the deontic modality in terms of the semantic and morphosyntactic aspects involved in the establishment of deontic acts in the interview genre. For this, we take as a basis the theoretical assumptions from the functionalist perspective, in which studies related to linguistic phenomena must be described and analyzed based on the effective use of language. In this sense, we resorted to the Mexico City Sociolinguistic Corpus (MCSC), from which we collected 20. After the analysis qualiquantitative, we found that the deontic source establishes a certain deontic modal value (obligation, permission, or prohibition) on the deontic target, considering the grammatical tense (present, simple future, or simple conditional) and the form of expression (modal auxiliaries) adequate so that they can mirror the speaker's communicative purposes in terms of asserting or mitigating deontic modal content deonticity expressed because this modality is considered as future-oriented.

Keywords: Functionalism. Deontic modality. Semantics. Morphosyntax. Spanish.

\footnotetext{
${ }^{1}$ Este trabalho tem relação com o projeto de pesquisa "A modalidade deôntica em língua espanhola (Etapa 2): análise funcionalista em corpus oral”, que foi coordenado pela Profa. Dra. Nadja P. P. Prata.

${ }^{2}$ Universidade Federal do Ceará, Programa de Pós-Graduação em Linguística, Fortaleza, CE, Brasil. Bolsista CAPES. Endereço eletrônico: janeeyrecaldas@ gmail.com.

${ }^{3}$ Universidade Federal do Ceará, Centro de Humanidades, Departamento de Letras Estrangeiras, Programa de Pós-Graduação em Linguística, Fortaleza, CE, Brasil. Endereço eletrônico: nadja.prata@ufc.br.

${ }^{4}$ Universidade Federal do Ceará, Programa de Pós-Graduação em Linguística, Fortaleza, CE, Brasil. Bolsista CAPES. Endereço eletrônico: andrethtzn@gmail.com.
} 


\section{Introdução}

Partindo do pressuposto de que a modalidade "constitui uma categoria linguística por meio da qual o falante codifica conteúdos e intenções" (PESSOA, 2011, p. 93), buscamos fazer uma análise das expressões que instauram a modalidade deôntica, sem excetuar a relação que há entre essas expressões com as características do gênero entrevista, uma vez que a perspectiva funcionalista entende que a língua funciona como um instrumento de interação social. Procuramos verificar se há também algum tipo de relação entre o uso dessas expressões e os valores modais deônticos, que, por sua vez, são instaurados por uma fonte deôntica sobre um alvo deôntico, os quais são engendrados no discurso em razão das intenções e dos propósitos comunicativos do falante. Nesse sentido, nos parece que o entrevistador, ao utilizar-se de questionamentos que favorecem a exposição de pontos de vista, como esclarece Rosa (2008), consiga que o entrevistado (falante) se introjete no discurso e expresse matizes de obrigação, permissão ou proibição para (não) realizar o evento designado pelo predicado, tendo em vista regras e normas de conduta sociais (modalidade deôntica).

No intuito de descrevermos e analisarmos a instauração da modalidade deôntica nas entrevistas do Corpus Sociolinguístico da Cidade do México (CSCM) e, com isso, averiguarmos o condicionamento dos aspectos semânticos sobre os aspectos morfossintáticos, estruturamos este trabalho da seguinte forma: na primeira seção, discorreremos acerca da perspectiva funcionalista, apresentando seus principais postulados; na segunda seção, exporemos sobre os estudos relativos à modalidade deôntica na seara linguística; na terceira seção, abordaremos os aspectos metodológicos desta pesquisa, como a delimitação do corpus e o estabelecimento das categorias de análise; na quarta seção, apresentaremos os resultados e discussões sobre o engendramento da modalidade deôntica nas entrevistas do CSCM, com base nas categorias de análise pautadas para esta pesquisa. Por fim, passaremos para as considerações finais e o referencial teórico desta pesquisa.

\section{A perspectiva funcionalista}

De acordo com Lyons (1987, p. 207), o funcionalismo como corrente teórica linguística pode ser caracterizado "pela crença de que a estrutura fonológica, gramatical e semântica das línguas é determinada pelas funções que têm de exercer nas sociedades em que operam". Tomando por base essas funções, Neves (2006) explica que se trata de "uma teoria que se liga, acima de tudo, aos fins a que serve as unidades linguísticas, o que é mesmo que dizer que o funcionalismo se ocupa, exatamente, das funções dos meios linguísticos de 
expressão". Ainda segundo a autora, é necessário que seja considerado o sistema linguístico em uso e que se considere, também, que a principal função da língua seria de atuar como instrumento de interação social entre seus usuários. A partir disso, surge a preocupação com as relações existentes entre a língua como um todo e as diversas modalidades de interação social, e não apenas com as características internas da língua. Dessa forma, a língua "não pode ser descrita como um sistema autônomo, já que a gramática não pode ser entendida como cognição e comunicação, processamento mental, interação social e cultura, mudança e variação, aquisição e evolução" (NEVES, 1997, p. 3).

De fato, há que se considerar, de acordo com Cunha (2011), que, quando se trata de fazer uma análise de cunho funcionalista, tanto os enunciados quanto os textos devem ser relacionados às chamadas funções que eles desempenham quando se dá a comunicação a nível interpessoal. Por isso, os funcionalistas buscam, exclusivamente, trabalhar com enunciados ou textos, orais ou escritos, produzidos por falantes reais em contextos comunicativos efetivos de fala, evitando o uso de todo e qualquer tipo de material que tenha sido criado/inventado, dissociado de sua função nos atos comunicativos realizados pelos falantes nativos ou não nativos de uma determinada língua. A causa dessa "preocupação" pelo uso de materiais autênticos se deve ao fato de que os funcionalistas concebem e entendem a língua(gem) como sendo uma "ferramenta" de interação social que se dá entre os falantes de uma comunidade linguística, alinhando-se, dessa forma, à tendência que analisa a relação existente entre linguagem e sociedade.

Dessa forma, o interesse das investigações linguísticas de cunho funcionalista sobrepassa a estrutura gramatical, procurando, nas mais diversas situações comunicativas, o material necessário para os distintos usos da língua pelos seus falantes, haja vista que "a abordagem funcionalista procura explicar as regularidades observadas no uso interativo da língua, analisando as condições discursivas em que se verifica esse uso" (CUNHA, 2011, p. 157). Castilho (2012) acrescenta que a corrente funcionalista não pode ser vista como uma abordagem monolítica, pois ela consegue reunir uma série de subteorias que coincidem na postulação de que uma língua apresenta funções cognitivas e sociais que desempenham um papel primordial na determinação das estruturas e dos sistemas que organizam a gramática de uma língua natural.

Ainda que haja uma diversidade de "funcionalismos", todos eles comungam, de acordo com Neves (2012), com alguns princípios que configuram suas bases epistemológicas: (i) concepção de língua como um sistema fluido e maleável, que é moldado a partir das pressões do uso; (ii) o caráter instrumental da linguagem, que serve como ferramenta de 
comunicação (visão teleológica); e (iii) a integração do componente pragmático que, por sua vez, governa a semântica e a morfossintaxe. Assim, a perspectiva funcionalista apregoa, com base em Dik (1989), que a pragmática é o quadro dentro do qual a semântica e a sintaxe devem ser estudadas; em que o sentido de análise linguística vai da pragmática à sintaxe, via semântica.

Desse modo, Dik (1989) especifica que as unidades linguísticas articuladas na interação comunicativa devem ser descritas e analisadas considerando a intenção comunicativa do falante e as informações pragmáticas do seu ouvinte. Dessa forma, a sintaxe (relativa à estruturação do discurso) está sujeita às designações semânticas que são atribuídas às expressões linguísticas pelo falante que, por sua vez, estão subordinadas aos aspectos pragmáticos que governam a interação comunicativa. Portanto, ao adotarmos uma abordagem funcionalista, parece-nos possível estudar modalidade deôntica, tendo em vista os aspectos semânticos - aqueles relativos à designação das unidades linguísticas referentes às regras e às normas de conduta - como condicionantes dos aspectos morfossintáticos envolvidos na instauração dos conteúdos modais deônticos.

Para que possamos verificar esses condicionamentos para a instauração da modalidade deôntica, é preciso que discorramos, como se verá na seção seguinte, acerca desta categoria modal que, segundo Hengeveld (2004), diz respeito às normas e às regras de conduta que são prescritas, reguladas ou avaliadas com base no que é aceito legalmente, moralmente e socialmente.

\section{A modalidade deôntica na seara linguística}

De acordo com Neves (2006), os estudos que pretendem demarcar e especificar a categoria modalidade são muito diversificados, haja vista que é perceptível tanto a própria variação dos conceitos referentes aos subtipos modais quanto às variações nesse campo de estudo, considerando que as mais diferentes orientações tipológicas buscam priorizar parâmetros que ora estão pautados nas noções de necessidade e possibilidade, ora se voltam para as questões factuais e não-factuais dos eventos, ora se direcionam em analisar a articulação ou não do elemento do desejo. Ainda conforme a autora, a problemática na hora de definir o real conceito de modalidade começa na tentativa de delimitá-la, já que esse conceito está relacionado não apenas ao significado das expressões modalizadoras, mas também ao delimitar as noções inscritas nesse domínio conceptual.

Neves (2006) ainda ressalta que há duas questões fundamentais que se deve considerar ao definir a modalidade: (i) a avaliação dos enunciados que são considerados como modais, 
averiguando se há, de verdade, a existência ou não da modalidade neles, sem que haja alguma marca de modalização explícita ou que seja perceptível, pelo menos em um ou outro elemento do enunciado; e (ii) a tentativa de estabelecer as chamadas "fronteiras" entre a lógica e a Linguística.

Podemos dizer que, ainda que haja diversas tipologias que delimitem e especifiquem a modalidade, esta categoria pode ser dividida em dois eixos principais: (i) o eixo do conhecimento, em que atua a modalidade epistêmica, relativa às crenças e aos saberes acerca do mundo real; e (ii) o eixo da conduta, em que atua a modalidade deôntica, que é relativa às regras e às normas de conduta que são impostas socialmente, legalmente ou moralmente.

Segundo Carretero (1992), a modalidade deôntica, nosso objeto de estudo, define-se como a possibilidade ou a necessidade que se possa determinar em relação às "leis sociais", das quais a possibilidade deôntica é entendida como permissão, ou seja, algo está permitido quando está sob as normas sociais; e a necessidade deôntica, que se denomina como obrigação, isto é, algo está obrigado quando é necessário que se aconteça para que se atue conforme as normas sociais.

Menezes (2011) ressalta que a modalidade deôntica está intrinsecamente relacionada à necessidade ou à possibilidade dos atos que são realizados pelos agentes moralmente responsáveis. Dessa forma, segundo a autora, entende-se que sentença modalizadora deôntica expressa uma proposição, isto é, expressa um enunciado que pode ser entendido como verdadeiro ou falso, mas não descreve, de fato, um ato em si. Quando o falante impõe uma obrigação da qual o seu ouvinte terá de agir (Abra a porta) ou refrear de agir (Não abra a porta) (MENEZES, 2011, p. 87), de determinado modo, obviamente, não se descreve nem o desempenho presente da ação e tampouco se descreve esse mesmo evento no futuro; descreve-se, nesse caso, um estado de coisas a ser obtido pelo falante caso o ouvinte execute o que lhe foi solicitado.

Assim, a modalidade deôntica, de uma maneira geral, consiste na seleção de formas de transmitir dada informação com base em valores morais, éticos, normas de conduta, etc., a variados sujeitos, uma vez que estes podem modificá-la. Desta forma, conforme nos informa Pérez Sedeño (2001, p. 102), “a modalidade se apresenta como escolha, consciente ou não, do enunciador"5. Entretanto, há algumas controvérsias a respeito da concepção de modalidade, posto que muitos autores acreditam que ela é uma característica inerente atribuída à oração

\footnotetext{
5 Tradução nossa. O original diz: "la modalidad se presenta como elección, consciente o no, del enunciador" conforme nos informa” (PÉREZ SEDEÑO, 2001, p. 102).
} 
(modus + dictum). No entanto, para esta pesquisa, iremos tratá-la como um conjunto de traços (semânticos e morfossintáticos) utilizados no ato comunicativo.

Deste modo, baseando-nos em Pessoa (2011), consideramos que a modalidade deôntica é relativa ao que é aceito em termos de regras e normas de conduta que podem ser reguladas, prescritas ou avaliadas por parte do falante ou de uma fonte externa a ele, e, por meio do qual, o falante codifica conteúdos e intenções, de modo que o seu discurso possa atuar sobre o ouvinte, ou melhor, que ele possa interagir com o ouvinte, de forma que amplie, modifique ou substitua sua informação pragmática já compartilhada entre ambos ou que ele almeja acrescentar.

Tendo sido feitas essas considerações acerca da modalidade deôntica, passaremos, na seção seguinte, para os aspectos metodológicos desta pesquisa, pontuando acerca da caracterização do corpus e o estabelecimento das categorias de análise.

\section{Metodologia da pesquisa}

No intuito de descrevermos e analisarmos o condicionamento dos aspectos morfossintáticos em vista dos aspectos semânticos envolvidos na instauração da modalidade deôntica no gênero entrevista, recorremos ao Corpus Sociolinguístico da Cidade do México $(\mathrm{CSCM}){ }^{6}$ que está composto por entrevistas individuais, do tipo semiestruturadas, e que foram elaboradas no âmbito do informante (trabalho ou residência). Reiteramos que, para esta pesquisa, não nos detivemos em questões sociolinguísticas, tais como sexo, faixa etária, grau de escolaridade, etc., restringindo-nos a descrever e analisar os usos dos modais deônticos nas construções discursivas dos entrevistados. O CSCM, em linhas gerais, está constituído por amostras de fala de 300 pessoas, constando de, aproximadamente, 500 horas de gravação. Com base nele, formamos um "subcorpus", composto por 20 entrevistas, que contém aproximadamente 22.000 palavras.

Em relação ao gênero textual oral que forma o corpus, destacamos que a entrevista é fundamentalmente dialogal, isto é, uma forma de interação social. De acordo com Medina (1995), a entrevista, nas suas diferentes aplicações, pode ser delimitada com uma técnica de interação social e de interpenetração informativa, propiciando com que haja uma quebra de isolamentos grupais, individuais, sociais; podendo também servir à pluralização de vozes e à distribuição democrática da informação. Como é sabido, a maioria das entrevistas consiste em interações orais, que, geralmente, são feitas oralmente para depois serem transcritas e

\footnotetext{
${ }^{6}$ Disponível em: https://lef.colmex.mx/corpus_sociolinguistico.html. Acesso: 01 jun. 2020.
} 
publicadas. Nas palavras de Gil (2010, p. 109), trata-se de "uma forma de diálogo assimétrico, em que uma das partes busca coletar dados e a outra se apresenta como fonte de informação."

Rosa (2008) acrescenta que os questionamentos feitos pelo entrevistador podem ser também de caráter subjetivo, no que tange às crenças e opiniões do entrevistado, levando ambos a um relacionamento recíproco, muitas vezes, de confiabilidade. Desse modo, esses questionamentos, geralmente, relacionam-se a uma avaliação de crenças, valores, atitudes, razões e motivos seguidos de fatos e comportamentos, o que pode culminar em regras e normas de conduta social. Nesse sentido, é provável que haja a instauração de obrigações, permissões ou proibições (modalidade deôntica) que recaiam sobre um dado participante designado pelo predicado ou sobre eventos reportados pelo entrevistado, geralmente relativos a normas e regras de conduta que devem ser seguidas por ele e/ou as demais pessoas do convívio social.

Portanto, o gênero entrevista pode propiciar que o entrevistado (falante) expresse a sua opinião e/ou a sua posição em relação ao que é articulado durante a entrevista, propiciando, dessa forma, o uso de modalizadores deônticos, que apresentam as seguintes características:

(i) os valores modais deônticos, que podem ser de obrigação, permissão ou proibição, conforme Lyons (1987), Palmer (1986), Pessoa (2007; 2011), Oliveira (2015) e Batista (2016).

(ii) os diferentes tipos de fonte deôntica, de onde advém a atitude modal deôntica instaurada, que, conforme Pessoa (2011), Oliveira (2015), Batista (2016) e Vidal (2016), podem ser: Enunciador, quando se tratar do próprio falante; Indivíduo, quando se tratar de um sujeito em particular que é reportado pelo falante; Instituição, quando se referir a um grupo institucional reportado pelo falante; e Domínio Comum, quando advir da coletividade, ou seja, preceitos morais estabelecidos socialmente.

(iii) os diferentes tipos de alvo deôntico, sobre quem recai a atitude modal deôntica instaurada, que, conforme Pessoa (2011), Oliveira (2015), Batista (2016) e Vidal (2016), podem ser: Enunciador, quando recair sobre o próprio falante; Indivíduo, quando recair sobre um sujeito reportado pelo falante no discurso; Instituição, quando recair sobre um grupo institucional específico; Domínio Comum, quando recair sobre a coletividade; Coenunciador, quando recair sobre quem o falante direciona o seu discurso; e Inexistente, quando se tratar de um evento que deve ser concretizado.

(iv) a marcação morfossintática de tempo gramatical, que, segundo Oliveira (2015), Batista (2016) e Vidal (2016), para a língua espanhola, pode ser: presente, pretérito perfecto 
simple, pretérito perfecto compuesto, pretérito imperfecto, pretérito pluscuamperfecto, futuro simple, futuro compuesto, condicional simple e condicional compuesto.

(v) as formas de expressão linguísticas que, de acordo com Oliveira (2015), Batista (2016) e Vidal (2016), podem ser em língua espanhola: auxiliares modais, verbos de significação plena, substantivos, adjetivos, advérbios, adjetivos em função predicativa, construções modalizadoras com verbo suporte, etc.

A análise dos dados se deu de modo: (i) qualitativo, haja vista que a categoria modalidade deôntica será descrita e analisada com base no que é predisposto pela perspectiva funcionalista e em trabalhos correlatos sobre essa categoria modal; e (ii) quantitativo, em virtude dos dados serem analisados com base em um programa estatístico para a geração das frequências das categorias de análise, no caso, o Statistical Package for the Social Sciences (SPSS) - versão 22 para o Windows.

Findos os aspectos relativos à delimitação do corpus e às categorias de análise, passarse-á, na seção seguinte, aos resultados e discussões da instauração da modalidade deôntica no gênero entrevista.

\section{Resultados e discussões}

Após a análise dos dados, constatamos 42 casos de modalizadores deônticos, que serão descritos e analisados seguindo o modelo top-down, dos aspectos semânticos (fonte, alvo e valores modais deônticos) aos aspectos morfossintáticos (tempo e formas de expressão).

No que tange à fonte deôntica, que diz respeito à origem da atitude modal deôntica instaurada, constatamos que a fonte Enunciador foi a mais usada, conforme mostra a Tabela 1:

Tabela 1 - A fonte deôntica em entrevistas do CSCM

\begin{tabular}{c|c}
\hline Fonte Deôntica & No. \\
\hline Enunciador & 37 \\
\hline Inexistente & 03 \\
\hline Não especificado & 01 \\
\hline Indivíduo & 01 \\
\hline Total & $\mathbf{4 2}$ \\
\hline
\end{tabular}

Fonte: Elaborada pelos autores com base nos dados do SPSS.

No caso de fonte Enunciador, a instauração dos valores parte do próprio falante, expressando-se de forma explícita ou implícita, em que este atua como o "porta-voz" da deonticidade expressa, prescrevendo ou regulando normas e regras de conduta sobre si e os demais. Vejamos em (1) e (2): 
(1) “E: ah/ ¿y qué más me platica de aquí/ del hospital? / alguna anécdota. I: del hospital/ ¿qué le podemos platicar? // bueno que este fue un hospital// que tuvo ciertal/ imagen/ no sabemos ni por qué pero/ generalmentel/ era presa de salir en los medios del..." (Entrevista 03)

["E: ah/ e as conversas daqui/ do hospital?/ alguma anedota I: do hospital/ que podemos conversar?// bem que este foi um hospital// que teve certa// imagem/ não sabemos nem o porquê mas/ geralmente// era presa de sair nos meios de/...]

(2) "I: aunque me agrada mucho// no te voy a decir que no me agrada/l es una carrera que < que:>// realmente me satisfacel/ pero que < que:>/ en un país en como el que vivimos// a veces es decepcionantel/ el que [los]. E: [claro]. I: profesionistas se tienen que dedicar a otra cosa/ que les deje más// económicamente < e:conómicamente>" (Entrevista 05)

[I: ainda que me agrade muito// não te direi que não me agrada// é uma carreira que// realmente me satisfaz// mas que/ em um país como o que vivemos// às vezes é decepcionante// o que [os] E: [claro] I: profissionais tenham que se dedicar a outra coisa/ que os deixem mais// economicamente]

Em (1), ao utilizar o modal poder, a fonte Enunciador instaura uma obrigação por meio do auxiliar, cujo alvo é a Instituição, o hospital, que está obrigado a realizar o evento descrito pelo predicado, platicar. Já em (2), percebemos que a fonte Enunciador parte do entrevistado, que expõe seu ponto de vista sobre a carreira, que recai sobre os profissionais, pois no país em que vivem, circunstâncias externas os obrigam a se dedicarem à outra coisa que os deixem em uma melhor situação econômica.

Por sua vez, a fonte Inexistente ocorreu em 3 casos, como exemplificado em (3):

(3)“E: la herreríal ¿la albañilería no le gustó? I: sí me gustal [pero]. E: [ajá]. I: cuando hay algún/ por ejemplo/ que hay que poner una ventana. E: ajá. I: y no haiga (sic) quien lo haga/ no haiga (sic) quien este [esté]. E: [ajá]. I: pues < pus> yo me lo chuto" (Entrevista 16)

[E: o ferreiro / você não gostou da alvenaria? E: sim, eu gosto / [mas]. E: [uh-huh]. I: quando houver algum / por exemplo / para colocar uma janela. E: uh-huh. I: e ninguém faz (sic) quem faz / ninguém faz (sic) quem é esse [é]. E: [uh-huh]. I: bem, eu sou péssimo]

Segundo a Real Academia Espanhola - RAE (2010), o operador modal deôntico haber que se trata de uma estrutura impessoal, na qual o sujeito inexistente parece impor o verbo haber. Em (3), portanto, o modal haber expressa uma obrigação, que não parte do falante nem de nenhum outro tipo de fonte, pois são as condições externas, haja vista que não há ninguém para fazer o serviço de pedreiro e que obrigue o entrevistado a ter que pôr a janela, ou seja, a obrigação não tem como origem uma fonte deôntica que instaura o valor.

Em relação aos tipos de fonte Indivíduo e Não-especificado, que somam juntos apenas 2 ocorrências, percebemos que há o compartilhamento de uma característica nos dois casos: o falante apenas reporta a existência da obrigação de agir para o outro participante, como podemos atestar em (4) e (5): 
(4) "I: y y deseo/ regresar a Tacubaya si Dios me lo permite [¿verdad? porque]. E: [¿a trabajar allá/ o?]” (Entrevista 18)

[I: e e desejo/voltar a Tacubaya se Deus me permite [verdade? porque] E: [para trabalhar lá/ ou?]

(5) "E: dime ¿tú que piensas? / porquel por qué será quel que sel que sel que somos tan pocas/ si aparentementel/ pues la mujer ya no estál o más bien ya no se le inculca la idea del de que tiene que ser ama de casa y... I: al sometimiento (risa)" (Entrevista 02)

[E: me diga o quê pensas?/ porque/ porque será que/ que se/ que se/ que somos tão poucas/ se aparentemente// pois a mulher já não está/ ou melhor já não inculcam nela a ideia de/ de que tem que ser dona de casa e I: à submissão (risos)]

Em (4), a fonte é do tipo Indivíduo, pois o entrevistado trata de reportar uma permissão instaurada por outra pessoa, Deus. É como se criasse uma enunciação dentro da outra, marcando o afastamento do falante em relação ao valor deôntico instaurado. Por seu lado, em (5), a fonte é do tipo Não-especificado, em que o entrevistador remete a uma fonte não especificada para ilustrar seu ponto de vista.

Averiguamos que os diferentes tipos de fonte deôntica parecem optar pelo presente do indicativo (tempo gramatical) e pelos auxiliares modais (forma de expressão) para a instauração do ato deôntico. De acordo com Oliveira (2015), o presente do indicativo reveste o ato deôntico instaurado de um valor mais assertivo, propiciando uma leitura do evento, sobre o qual a deonticidade recai, como sendo algo certo, passível de ser exequível e controlado [+controle]. Em relação ao emprego dos auxiliares modais, Batista (2016) especifica que a carga semântica dos verbos modais deônticos, tais como deber, poder, permitir, etc., intensificam a obrigatoriedade, permissividade ou proibição de (não) realização do ato deôntico. Dessa forma, o emprego dos auxiliares modais e do presente do indicativo reforçam o caráter de "moralmente responsável" e "revestido de autoridade" (LYONS, 1987) que se julga necessário que a fonte da atitude modal deôntica deva ter.

No que diz respeito ao alvo deôntico, sobre quem recai a deonticidade expressa, constatamos que o tipo Indivíduo é o mais usado, conforme Tabela 2:

Tabela 2 - O alvo deôntico em entrevistas do CSCM

\begin{tabular}{c|c}
\hline Alvo Deôntico & No. \\
\hline Indivíduo & 11 \\
\hline Enunciador & 10 \\
\hline Não-especificado & 07 \\
\hline Domínio Comum & 07 \\
\hline Coenunciador & 06 \\
\hline Instituição & 01 \\
\hline Total & $\mathbf{4 2}$ \\
\hline
\end{tabular}

Fonte: Elaborada pelos autores com base nos dados do SPSS. 
O tipo de alvo Indivíduo é o mais recorrente, com 11 casos, e se refere a um terceiroreportado, podendo ser definido ou não no encadeamento da entrevista, de acordo com Pessoa (2011), como podemos averiguar em (6) e (7):

(6) "I.... mis papás/ no son profesionistas/ sin embargo/ tuvieron ese/ empeño de decir/ "si yo no lo hice/ yo quiero que mis hijos lo hagan"/ y ellos nos dieron la oportunidad a todos// hubo quienes la aprovechamos bien/ hubo quien nol/ y pues < pus> con la pena/ ahorita se andan dando de golpes porque/ tienen que trabajar en un empleo/ en el que no le pagan lo quell él quisiera/ o lo que ella quisierall pero pues < pus> ni modo/ o sea" (Entrevista 02)

[I:....meus pais/ não são formados/ entretanto/ tiveram isso/ empenho de dizer/ "se eu não o fiz/ eu quero que meus filhos o façam"/ e eles deram oportunidade a todos// teve quem a aproveitasse bem/ teve quem não// e pois com a pena/ agora andam se lamentando porque/ têm que trabalhar em um emprego/ no que não o pagam o que// ele queria/ ou o que ela queria// mas pois nem modo/ ou seja]

(7)"E: porque uno se retiral y pierde todos los puntos y/ [prestaciones]. I: [y todo]/ entonces/ no puedes/ retirartel/ pero bueno/ llegará un momento en que/ habrá que hacerlo" (Entrevista 06)

[E: porque um se aposenta/ e perde os pontos e/ [prestações] I: [e tudo] / então/ não podes/ aposentar-te/ então/ chegará um momento em que/ terá que fazê-lo]

Em (6), o entrevistado instaura uma ação que recai sobre uma terceira pessoa ellos, seus irmãos, portanto, o alvo deôntico é o Indivíduo, pois se refere a um terceiro-reportado que está fora do circuito da fala e que, por sua vez, está obrigado a executar a ação descrita pelo predicado, no caso, trabalhar. Em (7), o alvo deôntico também é do tipo Indivíduo, em que o entrevistado instaura uma obrigação que recai sobre uma terceira pessoa genérica, que está implícita, expresso pelo artigo indefinido uno.

Como podemos verificar, a segunda maior ocorrência de alvo deôntico foi a do tipo Enunciador, o qual aparece em 10 casos, em que o falante remete ações que a ele caberiam ou não executar, como em (8):

(8)"I: [no] porque yo tengo/ mucho que hacer. E: ¿cómo qué? I: pues 〈 pus〉 como la tesis/ por ejemplo"(Entrevista 01)

[I: [não] porque eu tenho/ muito o que fazer E: como o quê? I: pois como a tese/ por exemplo]

Em (8), o falante instaura sobre si mesmo a obrigação de executar o evento contido no predicado, no caso, os seus afazeres diários. De acordo com Neves (2006), este tipo de obrigação é definido como "moral interna", isto é, o falante regula ou prescreve para si atos deônticos que devem ser realizados e por ele controlados [+controle].

Em seguida, constatamos o uso dos alvos deônticos Não-especificado e Domínio Comum, em (9) e (10), respectivamente: 
(9) "I: ... no sabemos ahora < ora> sí/ a ciencia cierta sil si nos váyamos (sic) a dedicar de lleno con este mismo trabajo o < o: / o pueda cambiar/ todavía no/ no nos estamos decididos/ bueno/ de mi parte pues aún/ creo quel aún no sé sil si siga con este negocio o/ o o cambie/ pero así/ de que..." (Entrevista 09 - G1)

[I: ...não sabemos agora se/ ao certo se/ se nós vamos (sic) a dedicar plenamente com este mesmo trabalho ou/ ou possa mudar/ ainda não/ não estamos decididos/ bom/ da minha parte pois ainda/ creio que/ ainda não sei se/ se sigo com este negócio ou/ ou ou mude/ mas assim/ de que...]

(10) "I: sí/ porque porque también/ se puede decir que cuando nosotros tatuábamos en aquel entonces/ el/ la onda era más como que más underground< ondergraund>/ ¿no? / no había una difusión tan cultural ni tan comercial como lo es ahora"(Entrevista 07 - G1)

[I: sim/ porque porque também/ se pode dizer que quando nos tatuávamos naquela altura/ o/ a moda era mais como que mais underground/ não? / não havia uma difusão tão cultural nem tão comercial como é agora]

Em (9), o alvo deôntico é Não-especificado, pois o entrevistado, ao instaurar a possibilidade deôntica, não estabelece claramente sobre quem recai o valor deôntico, mas estipula apenas a ação que deve ser concretizada, em que não sabem se vão se dedicar completamente ao trabalho ou se esta ação possa mudar. Em (10), o verbo poder, flexionado na terceira pessoa do singular e acompanhado da partícula de impessoalização "se" nos mostra que o alvo pode ser considerado como um Domínio Comum, pois percebemos um compartilhamento da permissão instaurada, em que o entrevistado compartilha a possibilidade deôntica com os demais, pois se pode dizer que quando eles se tatuavam a moda era mais underground.

Ainda com base na Tabela 2, percebemos que a quarta maior ocorrência de alvo deôntico foi a do tipo Coenunciador, com 6 casos. De acordo com Pessoa (2011), esse tipo de alvo deôntico se caracteriza por destinar, ao participante imediato da situação comunicativa, a obrigação, permissão ou proibição de (não) realização do evento designado pelo predicado, como podemos constatar em (11):

(11) "E: [no se] preocupel y/ usted puede atender a la gente ¿eh? / no. I: si las sél con todo gusto"(Entrevista 17 - G1)

[E: [não se] preocupe/ e/ você pode atender às pessoas certo? / não I: sim eu sei/ com todo prazer]

Em (11), recai sobre o Coenunciador, a quem o falante se direciona, a obrigação de realizar o evento sobre o qual recai a deonticidade, no caso, de realizar o atendimento das pessoas.

Por seu turno, o alvo deôntico menos instaurado é o de Instituição, em apenas 1 caso, que se refere à terceira pessoa do discurso, a qual é reportada pelo falante. Vejamos (12): 
(12) "E: ah/ ¿y qué más me platica de aquil del hospital? / alguna anécdota. I: del hospital/ ¿qué le podemos platicar? // bueno que este fue un hospital// que tuvo ciertal/ imagen/ no sabemos ni por qué pero/ generalmentell era presa de salir en los medios de/..." (Entrevista 03)

[E: ah / e o que mais você pode me contar aqui / o hospital? / Qualquer anedota. I: sobre o hospital / o que podemos lhe dizer? // bem, este era um hospital // que tinha uma certa // imagem / nem sabemos o porquê, mas / geralmente // foi preso na mídia de / ...]

Em (12), a instituição sobre qual recai a permissão é o hospital, neste caso, consideramo-lo como uma instituição por representar um setor de responsabilidade do Governo.

Assim como a fonte deôntica, o alvo deôntico parece optar pelo presente do indicativo para a instauração da modalidade deôntica, em que sobre este recai a obrigação, permissão ou proibição de (não) realizar o evento descrito pelo predicado. Nesses casos, atestamos também que os auxiliares modais são os mais recorrentes. Com base em Pessoa (2011) e Vidal (2016), ponderamos que a instauração da modalidade deôntica sobre o alvo deôntico no presente do indicativo e por meio de um auxiliar modal visa à assertividade sobre a qual o ato deôntico se reveste, em que sobre o alvo deôntico recai a responsabilidade de executar a ação designada pelo predicado, que é atenuada pela carga semântica obrigativa do modal deôntico empregado.

Quanto aos valores deônticos expressos pela fonte deôntica na instauração da modalidade deôntica sobre o alvo deôntico, podemos averiguar, por meio da Tabela 3, que o valor de obrigação é o mais recorrente:

Tabela 3 - Os valores modais deônticos em entrevistas do CSCM

\begin{tabular}{c|c}
\hline Valor modal deôntico & No. \\
\hline Obrigação & 26 \\
\hline Permissão & 11 \\
\hline Proibição (negação de permissão) & 04 \\
\hline Proibição (negação de obrigação) & 01 \\
\hline Total & $\mathbf{4 2}$ \\
\hline
\end{tabular}

Fonte: Elaborada pelos autores com base nos dados do SPSS.

De acordo com Vidal (2016), o valor modal de obrigação é o mais recorrente na instauração da modalidade deôntica, especificamente no gênero oral (entrevista), em razão de o falante optar por regular ou prescrever normas e regras de conduta que deverão ser executadas por aqueles a quem ele introjeta no discurso, podendo ser, como vimos anteriormente, sobre diferentes tipos de alvos deônticos. Vejamos (13) a (16): 
(13) "E: oye ¿y tu novio ya empezó la/ la tesis/ de maestría? / porquel cuando te dan beca creo que tienes [quel/ que empezar tu proyectol ¿no?]. I: [síl sí/ algo así, pero]/ tiene empezado el proyecto/ pero/ ¿me creerás que no sé ni de qué es?” (Entrevista 01)

[E: escuta, teu noivo já começou a/ a tese/ de mestrado? / por quê / quando te dão bolsa acredito que tens [que// que começar teu projeto/ não?] I: [sim/ sim/algo assim mas] / já começou o projeto/ mas/ tu acredita que não sei nem do que é?]

(14) “E: la herreríal ¿la albañilería no le gustó? I: sí me gustal [pero]. E: [ajá]. I: cuando hay algún/ por ejemplo/ que hay que poner una ventana. E: ajá. I: y no haiga (sic) quien lo haga/ no haiga (sic) quien este [esté]. E: [ajá] I: pues < pus> yo me lo chuto" (Entrevista 16)

[E: o ferreiro / você não gostou da alvenaria? E: sim, eu gosto / [mas]. E: [uh-huh]. I: quando houver algum / por exemplo / para colocar uma janela. E: uh-huh. I: e ninguém faz (sic) quem faz / ninguém faz (sic) quem é esse [é]. Eu: [uh-huh] Eu: bem, eu sou péssimo]

(15) "I: $\mathrm{mm} /$ es que < que::>/ como al año/ o sea no no no puedo< puedo:>/ definirlo porquel al añol o seal mi padre nos conociól/ bueno/ más bien me conoció a mí también/ al año”. (Entrevista 12)

[I: mm/ é que/ como no ano/ ou seja não não não posso/ defini-lo por quê/ no ano/ ou seja/ meu pai nos conheceu// bom/ me conheceu melhor/ no ano]

(16) "I: ...la secundaria/ aqui en la// en el municipio// y el trabajo ahorita/ pues súper cómodo/ porque no tengo que trasladarmel/ excepto porque estoy haciendo otras cosas por la mañana..." (Entrevista 02)

[I: ...o ensino médio aqui na// no município// e o trabalho agora mesmo// pois super cómodo// porque não tenho que me trasladar// exceto porque estou fazendo outras coisas pela manhã...]

Em (13), averiguamos a instauração do valor de obrigação estimulado pelo auxiliar modal tener. Assim, o entrevistador chama atenção para o fato de ser uma obrigação de quem recebe uma bolsa de mestrado ter que começar a fazer o projeto, pois circunstâncias externas o obrigam. Neste caso, o entrevistador pergunta à pessoa entrevistada se o noivo já começou a fazer a tese de mestrado, visto que, por ter recebido a bolsa, ele tem a obrigação moral de começá-lo. Em (14), o emprego do modal deôntico haber faz com que haja um descomprometimento por parte do falante com o ato deôntico instaurado, visto que ele emprega uma estrutura impessoal para se referir a obrigatoriedade de concretização de um evento, em que o sujeito inexistente parece impor o verbo haber. Em (15), constatamos o valor deôntico de negação de permissão, ou seja, uma proibição é instaurada pelo verbo “poder”, que é escopo de uma negação. Por sua vez, em (16), verificamos o valor deôntico de negação de obrigação, onde o entrevistado expressa que não há necessidade de se "trasladar", porque as circunstâncias, de estudar e trabalhar no município, fazem com que não haja a necessidade de sair de um lugar a outro.

Assim como na fonte deôntica e no alvo deôntico, a instauração dos valores modais deônticos parecem recorrer ao presente do indicativo para a instauração dos atos deônticos 
que são prescritos ou regulados pelo falante, fazendo uso de auxiliares modais. Considerando essa possível recorrência, pareceu-nos produtivo verificar a frequência do tempo gramatical e das formas de expressão em que a modalidade deôntica é instaurada no gênero entrevista do CSCM.

Com relação às formas de expressão da deonticidade em língua espanhola, para o nosso corpus, atestamos que os auxiliares modais são os mais recorrentes na instauração da modalidade deôntica, conforme Tabela 4:

Tabela 4 - As formas de expressão da modalidade deôntica em entrevistas do CSCM

\begin{tabular}{c|c}
\hline Formas de expressão & No. \\
\hline Auxiliares modais & 41 \\
\hline Verbos de significação plena & 01 \\
\hline Total & $\mathbf{4 2}$ \\
\hline
\end{tabular}

Fonte: Elaborada pelos autores com base nos dados do SPSS.

Vemos que auxiliares modais são os mais recorrentes para instauração de valores deônticos, sendo tener +que+infinitivo (21 ocorrências) > poder+infinitivo (14 ocorrências) > deber+infinitivo (4 ocorrências) > haber+que+infinitivo (2 ocorrências), como averiguamos de (17) a (20):

(17) "I: pues < pus> como mucha gente/por necesidad < necesidá>/ que no hay escuela pues < pus> [te tienes que ir]" (Entrevista 16)

[I: pois como muita gente/ por necessidade/ que não há escola pois [tu tens que ir]".?

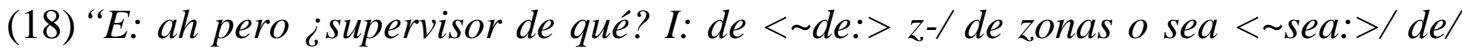
puede venir aquí o puede ir a otros lados así a dejar nóminas < nó:minas> y todo eso" (Entrevista 14)

[E: ah mas supervisor de quê? I: de zonas ou seja de/ poder vir aqui ou poder ir a outros lados assim pra deixar catálogos e tudo isso]

(19) "I: y también esto/ eh < eh:>/ me empezó a mí a darl/ a primero a enterarme/ de lo que era la floricultural para poder/ vender// [y ya luego]. E: [claro]. I: después también// para poder enseñar// porque yo veía que/ la gente venía y/ muchas de las veces// pues se quedaba con la duda/ cómo debía cultivar sus plantas// y así fu-/ eran las azaleas/ y eran las rosas// y como nosotros aquí tenemos varias exposiciones// entonces < entóns> tomé primero los temas/ de los cursos/ de las exposiciones que [tenemos]" (Entrevista 05)

[I: e também isto/ eh/ começou a// a primeiro compreender/ do que era a floricultura/ para poder/ vender// [e em seguida] E: [claro] I: depois também// para poder ensinar// porque eu via e/ muitas das vezes// pois ficava com a dúvida/ como devia cultivar suas plantas// e assim fo-// ram as azaleias// e eram as rosas// e como aqui nós temos várias exposições// então tomei primeiro os temas/ dos cursos/ das exposições que [temos]]

7 Vale ressaltar que na expressão [tu tens que ir] percebemos a inclusão da comunidade no qual está inserido o falante, é domínio comum]. 
(20) "E: porque uno se retira/ y pierde todos los puntos y/ [prestaciones]. I: [y todo]/ entonces/ no puedes/ retirartell pero bueno/ llegará un momento en quel habrá que hacerlo" (Entrevista 06)

[E: porque um se aposenta/ e perde os pontos e/ [prestações] I: [e tudo] / então/ não podes/ aposentar-te/ então/ chegará um momento em que/ terá que fazê-lo]

Em (17), verificamos que o modal tener+que+infinitivo, flexionado no presente do indicativo, fornece à sentença a ideia de obrigação, em que o entrevistado chama a atenção do entrevistador para o fato de que circunstâncias externas os obrigam (entrevistado e a comunidade no qual está inserido) a realizar a ação, pois estas os instigam a "terem que ir". Em (18), ao instaurar a permissão no presente do indicativo, observamos que o entrevistado deixa implícito, ao entrevistador, que ao supervisor de zonas lhe é concedido a faculdade "de poder vir ou poder ir" a outros lados a deixar catálogos. Assim, a utilização do modal poder expressa uma possibilidade deôntica de uma eventual ocorrência quando se propõe a ação.

Em (19), percebemos que o modal “deber" também fornece à sentença a ideia de obrigação, em que recai sobre o participante designado pelo predicado a obrigação de regar as plantas. Desse modo, o emprego do pretérito imperfeito do indicativo remete a uma obrigação, instaurada no momento da enunciação, que é referente a um evento anterior ao momento de fala, em que o sujeito introjetado no discurso, la gente, parece indicar a responsabilidade com que o falante cuida de suas plantas. Nesse sentido, o emprego do modal deôntico deber+infinitivo não permite uma leitura epistêmica, já que não expressa a avaliação do entrevistado sobre a verdade da proposição, isto é, o entrevistado não qualifica explicitamente seu comprometimento com relação a verdade da proposição. Em (20), a modalidade deôntica é instaurada por meio do operador modal haber+que+infinitivo, em que o falante se restringe a instaurar a obrigatoriedade de um evento, cujo valor modal deôntico é posterior ao momento de fala, o que é marcado pelo emprego do futuro simples do espanhol.

Como podemos ver, ainda que os auxiliares modais sejam os mais recorrentes na instauração da modalidade deôntica, averiguamos que os atos deônticos podem ser expressos em diferentes tempos gramaticais. Dessa forma, pareceu-nos necessário examinar as referências temporais empregadas pelo falante na regulação ou prescrição dos conteúdos modais deônticos, como apresentado na Tabela 5: 
Tabela 5 - Tempo gramatical dos modalizadores deônticos em entrevistas do CSCM

\begin{tabular}{c|c}
\hline Tempo gramatical & No. \\
\hline Presente & 34 \\
\hline Pretérito Imperfeito & 04 \\
\hline Condicional Simples & 03 \\
\hline Futuro do Presente & 01 \\
\hline Total & $\mathbf{4 2}$ \\
\hline
\end{tabular}

Fonte: Elaborada pelos autores com base no SPSS.

A partir dos dados da Tabela 5, verificamos que os dois tempos gramaticais de maior expressividade se trata do presente e do pretérito imperfeito do indicativo, sendo utilizados para asseverar a força do ato deôntico instaurado por meio do operador modal. Segundo a RAE (2010), o presente expressa a coincidência da situação designada como o momento da fala. Sendo esta coincidência pontual ou mais ampla. Os diferentes usos do presente recebem, frequentemente, denominações específicas: presente habitual (descreve ações repetidas); presente descritivo (refere-se a situações estáveis); e presente gnómico (próprio dos axiomas ou enunciados normativos). Vale ressaltar que, em qualquer caso, estas variedades são interpretações contextuais diversas do mesmo tempo verbal. Conforme Alarcos Llorach (2009), o presente do indicativo pode ainda ser empregado na expressão de ações futuras, o que, em certa medida, tem relação estreita com a modalidade deôntica; haja vista que os estados-de-coisas deônticos são de concretização em um momento posterior ao da enunciação, o que justificaria sua maior ocorrência no gênero analisado, em que o presente também situaria os valores modais deônticos para o momento da enunciação.

Por sua vez, o pretérito imperfeito, de acordo com a RAE (2010), localiza a situação em um momento anterior ao momento da fala e sem relação com ele, podendo indicar a repetição ou hábito; que, para a modalidade deôntica, pode se tratar de algo imposto socialmente. Por seu lado, ainda conforme a RAE (2010), o condicional simples do indicativo localiza um estado de coisas em uma situação não atual, seja esta pretérita (designa uma situação posterior a outra do passado) ou hipotética (expressa-se mediante construções de significado condicional); para estes casos, a modalidade deôntica poderia ser avaliativa, em que o falante avalia um dado evento sobre o qual recai a deonticidade, evento este nãocontrolado [-controle] e de pouca probabilidade de concretização [-factual].

Por fim, o futuro simples localiza uma situação em um ponto temporal posterior ao momento da fala e os enunciados deste tempo podem ser entendidos como ordens, advertências ou ameaças. Ainda em relação ao futuro simples, ponderamos, com base em Oliveira (2019), que o emprego deste tempo gramatical pode intensificar a força deôntica do evento sobre o qual recai a deonticidade, considerando que tanto o valor modal quanto o 
evento são de localização futura, o que é prototípico da modalidade deôntica, visto que, conforme Giomi (2010), ela é dita como um subtipo modal orientado-para-o-futuro.

\section{Considerações finais}

Tendo por base a nossa hipótese inicial de que os aspectos semânticos poderiam ser condicionadores dos aspectos morfossintáticos na instauração da modalidade deôntica, examinamos que isto se verifica se nos atentarmos ao fato de que a fonte deôntica (de onde advém a atitude modal deôntica) instaura um determinado valor modal deôntico (obrigação, permissão e proibição) sobre o alvo deôntico (sobre quem recai a atitude modal deôntica), considerando o tempo gramatical e a forma de expressão adequadas que possam refletir os seus propósitos comunicativos (atenuar ou asseverar o conteúdo modal deôntico instaurado, localizar o evento sobre o qual recai a deonticidade para o momento da enunciação ou para um tempo posterior, fazer com que a deonticidade expressa se revista de um caráter mais assertivo, etc.).

Em linhas gerais, constatamos que a entrevista, gênero essencialmente dialogal, expressa a modalidade deôntica em relação ao tempo gramatical por meio predominante do presente e do pretérito imperfeito do indicativo. Desse modo, a partir do nosso subcorpus, constatamos que, nesta interação social, entrevistador e entrevistado falam sobre fatos reais que ocorreram em um momento passado (anterior ao momento da fala) ou no presente (em um lugar específico). Verificamos também que, nas entrevistas, o valor deôntico com maior frequência é o valor de obrigação, manifestado principalmente pelo auxiliar modal tener+que+infinitivo, e o valor de permissão, manifestado pelo auxiliar modal poder+infinitivo.

Constatamos que a fonte com maior ocorrência foi do tipo Enunciador. Assim, o entrevistado, por deter mais o turno, utiliza-se dos modalizadores deônticos como estratégia, visando ampliar, modificar ou substituir informações do entrevistador. Entretanto, por se tratar de uma interação social, o entrevistador também faz uso de estratégias que visam a influir sobre a informação pragmática do entrevistado. Além disso, verificamos que os diferentes tipos de fonte deôntica buscam instaurar a modalidade deôntica, majoritariamente, sobre os alvos deônticos de tipo Indivíduo e Enunciador, em que estes estão obrigados a executar o ato deôntico instaurado. Nesses casos estudados, o alvo deôntico pode se tratar tanto de um terceiro-reportado quanto do falante.

Portanto, acreditamos que, para além dos aspectos semânticos apresentados nesta pesquisa como condicionadores dos aspectos morfossintáticos, haja outros parâmetros de 
análise que possam qualificar a modalidade deôntica no que tange à interação entre o entrevistador e o entrevistado, que poderiam condicionar tanto a semântica quanto a morfossintaxe das formas de expressão e do tempo gramatical dos operadores modais deônticos: os aspectos pragmáticos, que não foram contemplados nesta pesquisa.

\section{Referências}

ALARCOS LLORACH, E. Gramática de la Lengua Española. España: Espasa, 2009.

BATISTA, V. G. L. La modalidad deóntica en webcomentarios: un estudio funcionalista en lengua española. 2016. 81 f. TCC (Graduação em Letras) - Curso de Letras - Espanhol, Universidade Federal do Ceará, Fortaleza, 2016.

CARRETERO, M. Una propuesta de tipología de la modalidad: la aceptación como categoría modal. Dicenda: Cuadernos de Filología Hispánica, Madrid, n. 10, p. 41-61, 1991-1992. Disponível em: https://scholar.google.es/scholar?oi=bibs\&cluster=5702263619584047880\&btnI=1\&hl=es. Acesso em: 31 ago. 2020.

CASTILHO, A. T. Funcionalismo e gramática do português brasileiro. In: SOUZA, E. R. Funcionalismo linguístico: novas tendências teóricas. novas tendências teóricas. São Paulo: Contexto, 2012. p. 17-42.

CUNHA, A. F. Funcionalismo. In: MARTELOTTA, M. E. Manual de Linguística. São Paulo: Contexto, 2011. p. 157-176.

DIK, S. The theory of functional grammar. Dordrecht: Foris Publications, 1989.

GIL, A. C. Métodos e Técnicas de Pesquisa Social. São Paulo: Atlas, 2010.

GIOMI, R. Para uma caracterização semântica do futuro sintético romântico: descrição e análise dos valores do futuro do indicativo em português e em italiano. 2010. $232 \mathrm{f}$. Dissertação (Mestrado) (Mestrado em Linguística Geral e Românica) - Universidade de Lisboa, Lisboa, 2010.

HENGEVELD, K. Illocution, mood, and modality. In: BOOIJ, G.; LEHMANN, C.; MUGDAN, J. Morphology: a handbook on inflection and word formation. a handbook on inflection and word formation. Berlin: Mouton de Gruyter, 2004. p. 1190-1201.

LYONS, J. Linguagem e Linguística. Editora Guanabara: Rio de Janeiro, 1987.

MEDINA, C. A. Entrevista: o diálogo possível. São Paulo: Ática, 1995.

MENEZES, L. C. de. Expressões linguísticas modalizadoras deônticas em função argumentativa: um exercício de análise retórico-funcional. 2011. 334 f. Tese (Doutorado em Linguística) - Programa de Pós-Graduação em Linguística, Universidade Federal do Ceará, Fortaleza, 2011. 
NEVES, M. H. de M. A Gramática Funcional. São Paulo: Martins Fontes, 1997.

NEVES, M. H. de M Texto e Gramática. São Paulo: Contexto, 2006.

NEVES, M. H. de M. A gramática passada a limpo. São Paulo: Parábola, 2012.

OLIVEIRA, A. S. La modalidad deóntica en lengua española: un análisis funcionalista en editoriales. 2015. 136 f. TCC (Graduação em Letras) - Curso de Letras - Espanhol, Universidade Federal do Ceará, Fortaleza, 2015.

OLIVEIRA, A. S. A modalidade deôntica em função retórico-argumentativa nas Exortações Apostólicas do Papa Francisco. 2019. 34 f. Monografia (Especialização em Linguística) - Curso de Especialização em Linguística, Universidade de Araraquara, Araraquara, 2019.

PALMER, F. R. Mood and Modality. Cambridge: Cambridge University Express, 1986.

PÉREZ SEDEÑO, M. E. Subjetividad y modalidad lingüística. Revista Epos, Cádiz, v. 17, p. 57-70, 2001. Disponível em: http://e-spacio.uned.es/fez/eserv.php?pid=bibliuned:EposAE435A0F-5F4F-938A-6F29-05E57D0AEB99\&dsID=Documento.pdf. Acesso em: 10 mar. 2015.

PESSOA, N. P. Modalidade deôntica e persuasão no discurso publicitário. 2007. 151 f. Dissertação (Mestrado em Linguística) - Programa de Pós-Graduação em Linguística, Universidade Federal do Ceará, Fortaleza, 2007. Disponível em: http://www.repositorio.ufc.br/handle/riufc/6614. Acesso em: 20 dez. 2015.

PESSOA, N. P. Modalidade deôntica e discurso midiático: uma análise baseada no discurso funcional. 2011. 224 f. Tese (Doutorado em Linguística) - Programa de Pós-Graduação em Linguística, Universidade Federal do Ceará, Fortaleza, 2011. Disponível em: http://www.repositorio.ufc.br/handle/riufc/6097. Acesso em: 10 jan. 2016.

REAL ACADEMIA ESPAÑOLA. Nueva Gramática Básica de la lengua española. Madrid: Espasa Libros, 2010.

ROSA, M. V. de F. A entrevista na pesquisa qualitativa: mecanismo para validação de resultados. Belo Horizonte: Editora Autêntica, 2008.

VIDAL, R. P. La modalidad deóntica en lengua española: un análisis funcionalista en corpus oral. 2016. 102 f. TCC (Graduação em Letras) - Curso de Letras - Espanhol, Universidade Federal do Ceará, Fortaleza, 2016. Disponível em: http://www.repositoriobib.ufc.br/00002e/00002ef3.pdf. Acesso em: 20 maio 2017. 


\section{Sobre os autores}

Jane Eyre Martins Caldas (Orcid iD: http://orcid.org/0000-0002-3308-7910)

Mestranda no Programa de Pós-Graduação em Linguística da Universidade Federal do Ceará (UFC); graduada em Letras - Espanhol pela mesma instituição, com período de mobilidade acadêmica na Universidad Nacional de La Plata (UNLP/Argentina). Bolsista CAPES.

Nadja Paulino Pessoa Prata (Orcid iD: http://orcid.org/0000-0001-7861-7017)

Doutora e mestra em Linguística pela Universidade Federal do Ceará (UFC); graduada em Letras - Português/Espanhol pela mesma instituição. É professora do Departamento de Letras Estrangeiras e do Programa de Pós-Graduação em Linguística da Universidade Federal do Ceará (UFC). Realiza estágio de pós-doutorado na Universidad de Sevilla (US/Espanha).

André Silva Oliveira (Orcid iD: https://orcid.org/0000-0003-3448-0658)

Doutorando pelo Programa de Pós-Graduação em Linguística da Universidade Federal do Ceará (UFC); mestre em Linguística pela mesma instituição; especialista em Retórica e Argumentação pela Universidade de Araraquara (UNIARA); graduado em Letras Espanhol pela UFC. Bolsista CAPES.

Recebido em junho de 2020.

Aprovado em agosto de 2020. 